\title{
Vanishing pachy-choroid in pachychoroid neovasculopathy under long-term anti- vascular endothelial growth factor therapy
}

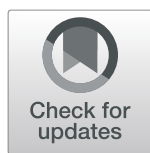

Benedikt Schworm, Nikolaus Luft, Leonie F. Keidel, Thomas C. Kreutzer, Tina R. Herold, Siegfried G. Priglinger and Jakob Siedlecki ${ }^{*}$ D

\begin{abstract}
Background: To investigate the diagnostic value of choroidal thickness in the definition of pachychoroid neovasculopathy (PNV), especially in eyes treated with anti-vascular endothelial growth factor (VEGF) therapy.

Methods: Twenty-two consecutive eyes of 11 patients with uni- or bilateral PNV were analyzed. Anti-VEGF treatment was correlated with changes in choroidal thickness on enhanced depth imaging optical coherence tomography.

Results: There were 14 eyes with PNV and 8 non-neovascular partner eyes. Mean age was $64.2 \pm 4.0$ (range: 60-72), total follow-up was $1.8 \pm 0.4(1-2)$ years. In PNV eyes, choroidal thickness at baseline was $400 \pm 58(269-485) \mu \mathrm{m}$. After two years and 13 anti-VEGF injections on average, a mean reduction of $-39 \pm 10(-26$ to -56$) \%$ to final $241 \pm 52(162-327) \mu \mathrm{m}$ was observed $(p<0.0001)$. Meanwhile, choroidal thickness in the partner eyes remained stable ( $p>0.13$ for all comparisons). A significant correlation of choroidal thinning and anti-VEGF injection rate was observed at year one $\left(r=-0.79 ; R^{2}=0.63 ; p=0.00073\right)$ and two $\left(r=-0.69 ; R^{2}=0.48 ; p=0.019\right)$. While 85.7\% of PNV eyes exceeded a pachychoroid threshold of $\geq 350 \mu \mathrm{m}$ at baseline, this figure dropped to $21.4 \%$ at year one and $0 \%$ at year two.
\end{abstract}

Conclusion: In PNV, choroidal thickness significantly decreases with anti-VEGF therapy, resembling a "vanishing pachy-choroid", and thus does not represent a valid long-term diagnostic criterium, especially when differentiating PNV from nAMD.

Keywords: Pachychoroid, Pachychoroid neovasculopathy, Central serous chorioretinopathy, Choroidal neovascularization, Optical coherence tomography, Vascular endothelial growth factor, Ranibizumab

\section{Key messages}

What was known: Pachychoroid neovasculopathy (PNV) is characterized by choroidal neovascularization above a thick choroid. What is new: In PNV, choroidal thickness decreases with increasing amounts of antiVEGF injections. Thus, choroidal thickness becomes an

\footnotetext{
* Correspondence: jakob.siedlecki@med.uni-muenchen.de Department of Ophthalmology, Ludwig-Maximilians-University, Mathildenstrasse 8, 80336 Munich, Germany
}

unreliable diagnostic criterium in pre-treated eyes when differentiating PNV from neovascular AMD.

\section{Background}

Pachychoroid disorders of the macula are frequently complicated by a choroidal neovascularization (CNV) [1-3]. These include central serous chorioretinopathy (CSC), which can develop secondary $C N V$ in up to $25 \%$ of cases [1, 3], and pachychoroid neovasculopathy

(c) The Author(s). 2021 Open Access This article is licensed under a Creative Commons Attribution 4.0 International License, which permits use, sharing, adaptation, distribution and reproduction in any medium or format, as long as you give appropriate credit to the original author(s) and the source, provide a link to the Creative Commons licence, and indicate if changes were made. The images or other third party material in this article are included in the article's Creative Commons licence, unless indicated otherwise in a credit line to the material. If material is not included in the article's Creative Commons licence and your intended use is not permitted by statutory regulation or exceeds the permitted use, you will need to obtain permission directly from the copyright holder. To view a copy of this licence, visit http://creativecommons.org/licenses/by/4.0/ The Creative Commons Public Domain Dedication waiver (http://creativecommons.org/publicdomain/zero/1.0/) applies to the data made available in this article, unless otherwise stated in a credit line to the data. 
(PNV), which represents $\mathrm{CNV}$ atop areas of thickened choroid without prior evidence of CSC [4].

Recently, Hwang et al. [5] described a significant overlap of multimodal imaging findings in PNV and CSC complicated by $\mathrm{CNV}$, and suggested that both might be variants of the same disease. Simultaneously, we have recently suggested the use of the term $P N V$ as a general term for both PNV and CSC complicated by CNV to facilitate the distinction of neovascular pachychoroid disorders from non-neovacular (CSC, pachychoroid pigment epitheliopathy (PPE)) and neovascular pachychoroid disease with an aneurysmal phenotype (polypoidal choroidal vasculopathy/or aneurysmal type $1 \mathrm{CNV}$ ) [6].

Due to the high amount of cumulative damage required for $\mathrm{CNV}$ formation in pachychoroid disease, patients with PNV are usually older than patients with pachychoroid pigment epitheliopathy (PPE) or acute CSC [2]. Resultingly, PNV is often mistaken as, sometimes unresponsive, neovascular age-related macular degeneration (nAMD) [7], which can be aggravated by the $\mathrm{CNV}$-induced disruption of retinochoroidal tissue, especially if the $\mathrm{CNV}$ is mimicking drusenoid pigment epithelium detachments [8].

Although both nAMD and PNV react well to antivascular growth factor (VEGF) therapy [9-11], a thorough discrimination between both entities is essential for further research endeavors targeting the very different underlying etiopathologies beyond anti-VEGF (drusen accumulation with age-related choroidal thinning vs. choroidal thickening and Haller vein dilation).

Based on the definition of pachychoroid disease, the presence of a thick choroid should be a prerequisite for its diagnosis [2]. On the other hand, choroidal thickness is known to decrease with age $[12,13]$, and moreover, might be influenced by disease duration, complications such as $\mathrm{CNV}$ and resulting disease-modifying intravitreal anti-VEGF therapy influencing choroidal permeability and CNV [14-16]. The following study was therefore designed [17] to investigate the validity of choroidal thickness in the definition of late-stage neovascular nonaneurysmatic pachychoroid disease, and its ability to discriminate between pachychoroid disease and nAMD.

\section{Methods}

\section{Participants}

For this retrospective cohort study, all eyes presenting with treatment-naïve $\mathrm{CNV}$ at the Ludwig MaximiliansUniversity Munich, Germany, between January 2017 and May 2019 were screened for cases of PNV eligible for inclusion in this study, defined as: (i) Presence of a pachychoroid, defined as a) a subfoveal choroidal thickness $\geq$ $350 \mu \mathrm{m}$, or $\geq 250 \mu \mathrm{m}$ with a previous pre-documented history of CSC, b) with the presence of pachyvessels, defined as dilated lumina of the Haller's layer and c) an attenuation of the overlying choroidal structures; (ii) Presence of a CNV; (iii) absence of CNV aneurysms/ polyps; (iv) anti-VEGF therapy with a follow-up of $\geq 1$ year; (v) absence of classic drusen or reticular pseudodrusen on either eye; (vi) absence of antimineralocorticoid or photodynamic therapy during follow-up; (vii) absence of confounding comorbidities (diabetic retinopathy, hereditary retinal disease, diseases of the vitreoretinal interface, status after vitrectomy, optic media opacification impeding sufficient image quality). Unaffected partner eyes were included as a control group. Institutional review board approval was obtained for this retrospective chart review, and the study adhered to the tenets of the Declaration of Helsinki. At the moment of data analysis, ethic's committee approval was not required for retrospective, non-interventional studies.

Epidemiological data was obtained from each patient, including age, gender, previous ocular comorbidities and procedures, date of first diagnosis of PNV, date of first anti-VEGF injection, number of anti-VEGF injections, and objective refraction-based Snellen chart visual acuity at baseline and at years 1 and 2, which was later converted to $\log M A R$ for analysis.

\section{Multimodal imaging}

Multimodal imaging (all on Spectralis HRA + OCT, Heidelberg Engineering, Heidelberg, Germany) was performed after pupil dilation with topical tropicamide $1 \%$ and phenylephrine $2.5 \%$. It included enhanced depth (EDI) spectral domain optical coherence tomography (SD-OCT) and near-infrared (NIR) confocal laser scanning ophthalmoscopy (CSLO) in every eye at each visit. OCT angiography was performed in every eye at baseline. Blue-autofluorescence (BAF) CSLO, fluorescein (FA) and/or indocyanine green (ICG) angiography and additional OCT angiography scans were performed at the investigator's discretion. Only OCT images with a quality score of 20 and above were analyzed.

\section{Measurement of choroidal thickness}

Choroidal measurements were obtained using the Heidelberg Eye Explorer (Heidelberg Engineering, Heidelberg, Germany) on enhance depth imaging OCT images in the $1: 1 \mu \mathrm{m}$ setting by two readers (JS, LK). In the case of disagreement, defined as a difference of $>10 \mu \mathrm{m}[18$, 19], a third senior reader was consulted (BS). Sub-foveal choroidal thickness (SFCT) was measured directly underneath the fovea from the outer portion of the retinal pigment epithelium to the sclerochoroidal interface. Two further choroidal thickness measurements were obtained in analogous fashion in a distance of $1500 \mu \mathrm{m}$ nasally and temporally of the fovea. 


\section{Anti-VEGF treatment}

Treatment was primarily performed using a treat \& extend regimen as described previously [20, 21]. In brief, each newly diagnosed CNV lesion was treated with an upload of three monthly injections of Ranibizumab (Novartis Pharma AG, Basel, Switzerland), after which the interval was extended or shortened by two weeks based on the absence or presence of new CNV activity. CNV activity was defined on OCT as (I) any new macular fluid, including SRF, (II) pigment epithelium detachment (PED) increasing central macular thickness > $50 \mu \mathrm{m}$, (III) new or increasing macular hemorrhage, or (IV) a decrease in visual acuity $\geq 1$ Snellen chart line. Minimum and maximum interval between injections were 4 and 12 weeks, respectively. In the case of CNV reactivation, treatment was again started as in a newly diagnosed lesion. When patients did not consent with a treat \& extend regimen, a pro-re-nata regimen was performed, using the same reactivation criteria as mentioned above.

\section{Statistical analysis}

All data were gathered and analyzed in Microsoft Excel spreadsheets (Version 16.23 for Mac; Microsoft, Redmond, WA, USA). Statistical analysis was performed in SPSS Statistics 25 (IBM Germany GmbH, Ehningen, Germany). The level to indicate statistical significance was defined as $p<0.05$. The Shapiro-Wilk and Kolmogorov-Smirnov tests were employed to test for normal distribution. Statistical analyses of intra-group differences were performed using the dependent twotailed Student t-test and the Wilcoxon signed rank test. A repeated measures ANOVA test was used to compensate for multiple testing, if applicable. Pearson's correlation coefficient was used to test associations of dependent and independent variables.

\section{Results}

\section{Baseline demographics}

Twenty-two eyes of 11 patients were included in the analysis. Detailed baseline parameters of the study cohort can be found in Table 1. In brief, 14 (63.6\%) out of the 22 eyes had a diagnosis of PNV, and 8 eyes (36.4\%) were partner eyes without signs of neovascularization. Mean age was $64.2 \pm 4.0$ (range: $60-72$ ) years with a female to male ratio of 4 / 7 (36.4 / 63.6\%). Total followup was $1.8 \pm 0.4(1-2)$ years. All eyes were available for the one-year analysis, and $77.2 \%$ were available at year two. In total, 10 of the 22 eyes (45.5\%) had a history of CSC. In the anti-VEGF treatment group, these were 9 out of 14 eyes $(64.3 \%)$. In the control group, one eye out of 8 had a history of CSC (12.5\%), while 4 had PPE $(50 \%)$.
Table 1 Baseline demographic data

\begin{tabular}{|c|c|}
\hline No. of eyes (n) & 22 \\
\hline PNV eyes & 14 \\
\hline Right / Left & $8 / 6$ \\
\hline Partner eyes & 8 \\
\hline Right / Left & $3 / 5$ \\
\hline No. of patients (n) & 11 \\
\hline Gender (m/f) & $7 / 4$ \\
\hline Mean age (years) & $64.2 \pm 4.0$ (range: $60-72$ ) \\
\hline Mean follow-up (y) & $1.8 \pm 0.4(1.00-2.00)$ \\
\hline Year 1 & $22(100 \%)$ \\
\hline Year 2 & $17(77.2 \%)$ \\
\hline \multicolumn{2}{|c|}{ Pachychoroid disease stage } \\
\hline \multicolumn{2}{|l|}{ PNV eyes $(n=14)$} \\
\hline 1 (PPE) & 0 \\
\hline $2(\mathrm{CSC})$ & 0 \\
\hline 3 (PNV) & $14(100 \%)$ \\
\hline 4 (PAT1) & 0 \\
\hline \multicolumn{2}{|l|}{ Partner eyes $(n=8)$} \\
\hline 1 (PPE) & $4(50 \%)$ \\
\hline $2(\operatorname{CsC})$ & $1(12.5 \%)$ \\
\hline $3(\mathrm{PNV})$ & 0 \\
\hline 4 (PAT1) & 0 \\
\hline \multicolumn{2}{|l|}{ Macular morphology } \\
\hline \multicolumn{2}{|l|}{ PNV eyes } \\
\hline Subretinal fluid & $14(100 \%)$ \\
\hline Intraretinal fluid & 0 \\
\hline Flat, irregular PED & $14(100 \%)$ \\
\hline CNV & $14(100 \%)$ \\
\hline \multicolumn{2}{|l|}{ Partner eyes } \\
\hline Subretinal fluid & 1 \\
\hline Intraretinal fluid & 0 \\
\hline Flat, irregular PED & 0 \\
\hline CNV & 0 \\
\hline \multicolumn{2}{|c|}{ Mean Ranibizumab injections } \\
\hline \multicolumn{2}{|l|}{ PNV eyes } \\
\hline Year 1 & $7.0 \pm 2.9(2-11)$ \\
\hline Year 2 & $6.5 \pm 3.1(1-10)$ \\
\hline \multicolumn{2}{|l|}{ Partner Eyes } \\
\hline Year 1 & 0 \\
\hline Year 2 & 0 \\
\hline
\end{tabular}

\section{Macular morphology}

At baseline, all eyes (100\%) diagnosed with PNV had subretinal fluid and a flat, irregular PED forming a double-layer sign. The presence of a type $1 \mathrm{CNV}$ within the flat PED was confirmed on OCT angiography in all 
eyes $(100 \%)$. No eye showed intraretinal fluid or a type 2 $\mathrm{CNV}$ configuration at baseline.

In the 8 partner eyes, no case of flat irregular PED, $\mathrm{CNV}$ or intraretinal fluid was observed. Five eyes $(62.5 \%)$ showed characteristics of the non-neovascular spectrum of pachychoroid disorders. In 4 (50.0\%), pachychoroid pigment epitheliopathy (PPE) was found, while one eye (12.5\%) displayed CSC with subretinal fluid at baseline, which resolved without treatment after 9 weeks of follow-up.

\section{Anti-VEGF treatment}

In the first year, mean $7.0 \pm 2.9(2-11)$ injections were given. Due to disease inactivation after two injections, one patient expressed the wish to stop treatment on one eye (7.1\%). All other patients received an upload of Ranibizumab (92.9\%), after which three (23.1\%) asked for a continuation of treatment using a pro-re-nata regimen. In the remaining 10 patients, a treat \& extend regimen with mean $8.5 \pm 1.6(8-11)$ injections was performed. In the second year, 11 out of the 14 PNV eyes $(78.6 \%)$ were treated with a mean of $6.5 \pm 3.1$ (1-10) injections. In these 11 eyes, a treat \& extend regimen was used in 9 (81.8\%), and a pro-re-nata regimen in 2 eyes (18.2\%).

\section{Subfoveal, nasal and temporal choroidal thickness}

Choroidal thickness during follow-up is presented in detail in Fig. 1 and Table 2. In PNV eyes, mean SFCT at baseline was $400 \pm 58(269-485) \mu \mathrm{m}$. At year one, it significantly decreased to $295 \pm 53(210-393) \mu \mathrm{m}(-25 \%$; $p<0.0001)$. In year two, SFCT further decreased to $241 \pm 52(162-327) \mu \mathrm{m}$, resulting in an additional $20 \%$ reduction $(p=0.0003)$. Comparing baseline to end of follow-up at year two, a mean reduction of $-39 \pm 10$ (26 to -56$) \%$ occurred. Mean nasal choroidal thickness (CT) at baseline was $312 \pm 42(243-368) \mu \mathrm{m}$. At year one, a decrease to $249 \pm 47$ (180-332) was observed ($19 \% ; p<0.0018)$. In year two, nasal CT further decreased to $222 \pm 40(178-315) \mu \mathrm{m}$, resulting in an additional $12 \%$ reduction $(p=0.017)$. Comparing baseline to end of follow-up at year two, a mean reduction of $-27 \pm 16$ (52 to 1$) \%$ occurred. Mean temporal choroidal thickness (CT) at baseline was $324 \pm 71(174-404) \mu \mathrm{m}$. At year one, a decrease to $249 \pm 51(139-316) \mu \mathrm{m}$ was observed $(-23 \% ; p<0.0001)$. At year two, temporal CT further decreased to $220 \pm 46(108-263) \mu \mathrm{m}$, resulting in an additional $11 \%$ reduction $(p=0.031)$. Comparing baseline to end of follow-up at year two, a mean reduction of $-29 \pm 15$ (-56 to 2$) \%$ occurred.

At baseline, the 8 partner eyes showed a mean SFCT of $355 \pm 50(271-450)$, a nasal CT of $264 \pm 44(183-310)$ and a temporal CT of $301 \pm 50(220-384) \mu \mathrm{m}$. At year one and two, mean SFCT, nasal and temporal CT remained unchanged ( $p>0.13$ for all comparisons).

\section{Correlation of choroidal thickness reduction and anti- VEGF injections}

To test the hypothesis whether the absolute number of anti-VEGF injections correlated with the reduction in choroidal thickness, the Pearson correlation coefficient was calculated. In the first year, a significant strong negative correlation was found $\left(\mathrm{r}=-0.79 ; \mathrm{R}^{2}=0.63 ; p=\right.$ .00073; Fig. 2), which was also maintained in the second year $\left(\mathrm{r}=-0.69 ; \mathrm{R}^{2}=0.48 ; p=.019\right)$.

\section{Choroidal thickness and pachychoroid threshold values}

At baseline, 12 out of the 14 PNV eyes (85.7\%) exceeded a pachychoroid threshold of $\geq 350 \mu \mathrm{m}$. After anti-VEGF treatment, at year one, this figure dropped to 3 eyes (21.4\%; Fig. 3), and at year two, no eye fulfilled the prespecified threshold.

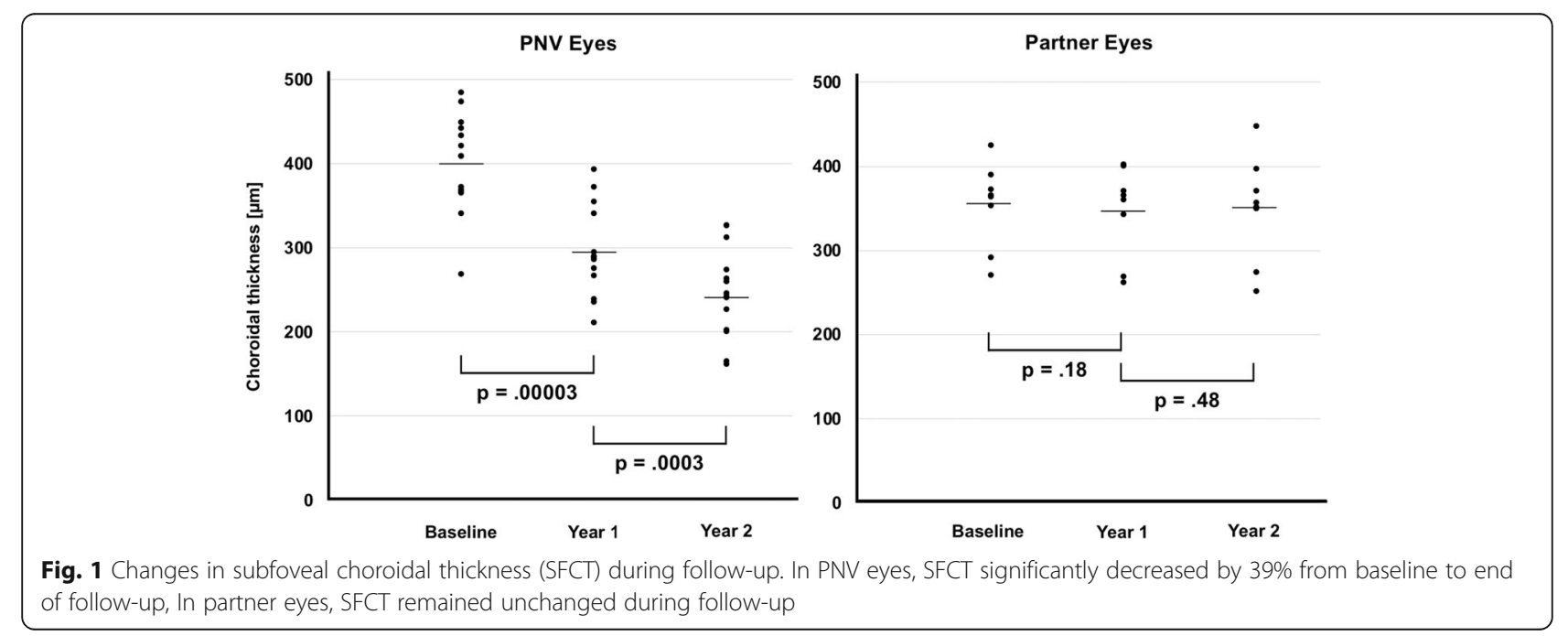


Table 2 Choroidal thickness in PNV and partner eyes during follow-up

\begin{tabular}{|c|c|c|c|c|c|c|c|}
\hline & $\begin{array}{l}\text { Baseline choroidal } \\
\text { thickness }(\mu \mathrm{m})\end{array}$ & $\begin{array}{l}\text { Year } 1 \\
\text { choroidal } \\
\text { thickness }(\mu \mathrm{m})\end{array}$ & $\%$ reduction & $p$ & $\begin{array}{l}\text { Year } 2 \\
\text { choroidal } \\
\text { thickness }(\mu \mathrm{m})\end{array}$ & $\%$ reduction & $p$ \\
\hline \multicolumn{8}{|c|}{ Eyes with PNV } \\
\hline subfoveal & $400.3 \pm 57.9(269-485)$ & $\begin{array}{l}295.3 \pm 52.8(210- \\
393)\end{array}$ & $\begin{array}{l}-0.25 \pm 0.14(-0.50 \\
\text { to }-0.01)\end{array}$ & .00003 & $\begin{array}{l}241.4 \pm 52.4(162- \\
327)\end{array}$ & $\begin{array}{l}-0.20 \pm 0.13(-0.38 \\
\text { to }-0.04)\end{array}$ & .0003 \\
\hline nasal & $311.9 \pm 42.1(243-386)$ & $\begin{array}{l}249.0 \pm 47.2(180- \\
332)\end{array}$ & $\begin{array}{l}-0.19 \pm 0.17(-0.49 \\
\text { to } 0.07)\end{array}$ & .0018 & $\begin{array}{l}221.5 \pm 40.2(178- \\
315)\end{array}$ & $\begin{array}{l}-0.12 \pm 0.16(-0.35 \\
\text { to } 0.15)\end{array}$ & .017 \\
\hline temporal & $323.9 \pm 71.1(174-404)$ & $\begin{array}{l}248.6 \pm 50.8(139- \\
316)\end{array}$ & $\begin{array}{l}-0.23 \pm 0.09(-0.38 \text { to } \\
-0.02)\end{array}$ & $\begin{array}{l}< \\
0.00001\end{array}$ & $\begin{array}{l}219.5 \pm 45.8(108- \\
263)\end{array}$ & $\begin{array}{l}-0.11 \pm 0.15(-0.43 \\
\text { to } 0.17)\end{array}$ & .031 \\
\hline \multicolumn{8}{|l|}{ Partner eyes } \\
\hline subfoveal & $354.5 \pm 50.3(271-425)$ & $\begin{array}{l}347.5 \pm 54.1(262- \\
403)\end{array}$ & $\begin{array}{l}-0.02 \pm 0.04(-0.10 \text { to } \\
0.03)\end{array}$ & .19 & $\begin{array}{l}350.5 \pm 74.7(252- \\
449)\end{array}$ & $\begin{array}{l}-0.01 \pm 0.10(-0.14 \\
\text { to } 0.15)\end{array}$ & .48 \\
\hline nasal & $264.1 \pm 43.8(183-310)$ & $\begin{array}{l}257.1 \pm 55.7(158- \\
324)\end{array}$ & $\begin{array}{l}-0.03 \pm 0.13(-0.16 \text { to } \\
0.18)\end{array}$ & .57 & $\begin{array}{l}266.5 \pm 55.1(183- \\
324)\end{array}$ & $\begin{array}{l}0.03 \pm 0.12(-0.13 \text { to } \\
0.23)\end{array}$ & .50 \\
\hline \multirow[t]{2}{*}{ temporal } & $301.4 \pm 50.0(220-384)$ & $\begin{array}{l}306.6 \pm 56.7(195- \\
364)\end{array}$ & $\begin{array}{l}0.02 \pm 0.11(-0.12 \text { to } \\
0.16)\end{array}$ & .67 & $\begin{array}{l}262.3 \pm 33.6(200- \\
296)\end{array}$ & $\begin{array}{l}-0.07 \pm 0.09(-0.17 \\
\text { to } 0.07)\end{array}$ & .13 \\
\hline & & \multicolumn{3}{|c|}{$\begin{array}{l}\text { correlation with number of injections: } \\
r=-0.79 ; R^{2}=0.63 ; p=.00073\end{array}$} & \multicolumn{3}{|c|}{$\begin{array}{l}\text { correlation with number of injections: } \\
r=-0.69 ; R^{2}=0.48 ; p=.019\end{array}$} \\
\hline
\end{tabular}

Considering a pachychoroid threshold of $\geq 300 \mu \mathrm{m}, 13$ out of the 14 PNV eyes (92.9\%) exceeded this value at baseline. After anti-VEGF treatment, this figure dropped to 4 eyes (28.5\%; Fig. 3 ) at year one, and one eye (9.1\%) at year two.

Of the 8 partner eyes, 6 (75\%) showed a pachychoroid $>350 \mu \mathrm{m}$ at baseline, which remained stable with 6 eyes (75\%) at year one and 4 out of 6 eyes $(66.7 \%)$ at year

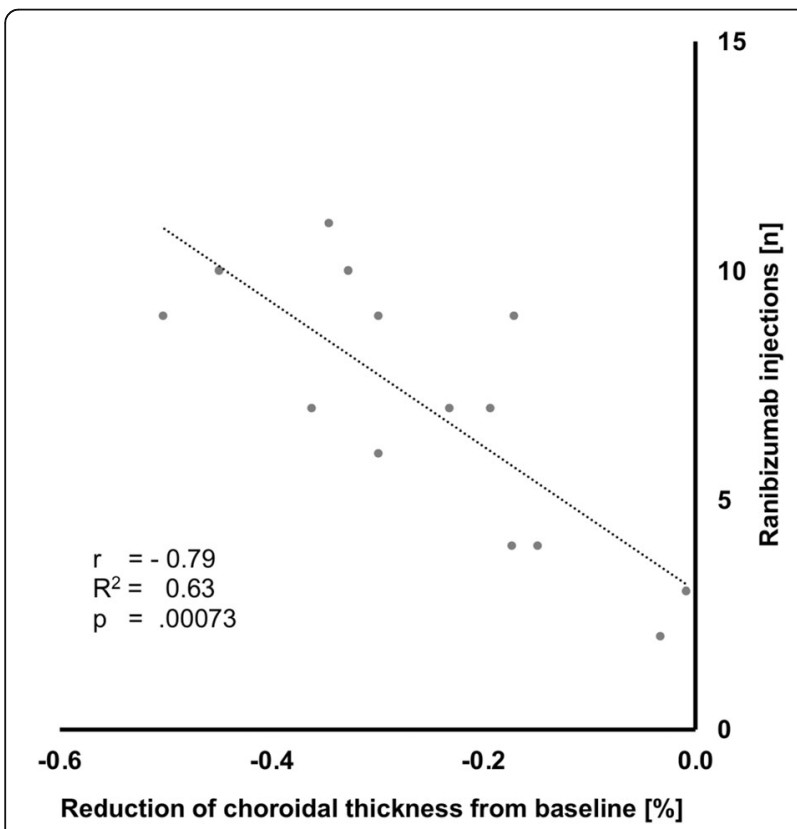

Fig. 2 Correlation of subfoveal choroidal thinning and amount of anti-VEGF injections in the first year. A significant strong negative correlation was found $\left(r=-0.79 ; R^{2}=0.63 ; p=.00073 ;\right.$ Fig. 1$)$. In year two, this correlation was maintained $\left(r=-0.69 ; R^{2}=0.48 ; p=.019\right)$ two. The exact same numbers apply for a pachychoroid threshold of $>300 \mu \mathrm{m}$.

\section{Visual acuity}

In the PNV eyes, a mean visual acuity of $0.58 \pm 0.39$ (0.1-1.3) $\log$ MAR at baseline was maintained at year one with $0.54 \pm 0.32(0.1-1.0) \log$ MAR and at year two with $0.68 \pm 0.36(0.1-1.3) \operatorname{logMAR}(p=0.63)$. In the partner eyes, the baseline visual acuity of $0.21 \pm 0.24$ (0.0-0.70) $\log$ MAR remained unchanged at year one with $0.28 \pm 0.37(0.0-1.0) \log$ MAR and at year two with $0.22 \pm 0.39(0.0-1.0) \log$ MAR $(p=0.88)$.

\section{Adverse events}

No serious adverse events (no endophthalmitis, no retinal detachment, and no macular hemorrhage involving the fovea and requiring pneumatic displacement) were observed during the study period.

\section{Discussion}

In the present study, we sought to test whether choroidal thickness represents a stable, reliable diagnostic criterium to discriminate between pachychoroid and non-pachychoroid neovascular disease, in this case pachychoroid neovasculopathy (PNV).

In accordance with the literature [2, 4, 11, 22], we found that the PNV eyes included in our study showed an above-average mean subfoveal choroidal thickness (SFCT) of $400 \mu \mathrm{m}$, which is well above the generally established threshold of $>350 \mu \mathrm{m}$ considered to represent a pachychoroid [2]. As a new finding, we however describe that this "pachy-choroid" actually disappears with anti-VEGF therapy, and thus does not represent a 


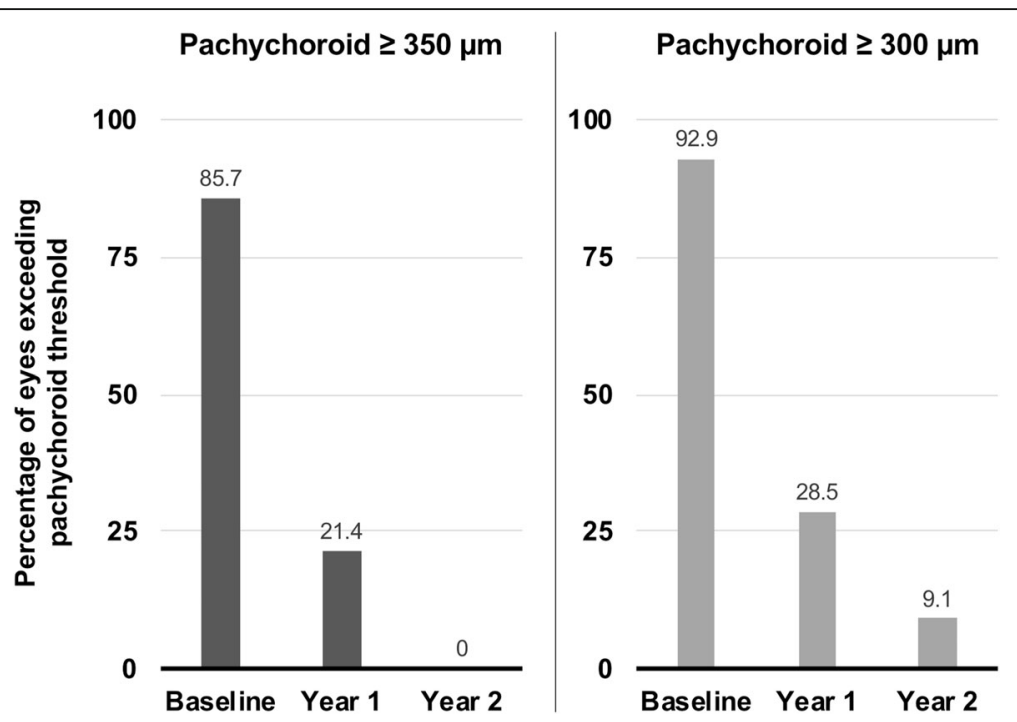

Fig. 3 Percentage of PNV eyes fulfilling pachychoroid disease diagnostic thresholds at baseline, year one and two. At baseline, 12 out of the 14 PNV eyes (85.7\%) exceeded a pachychoroid threshold of $\geq 350 \mu \mathrm{m}$. After anti-VEGF treatment, at year one, this figure dropped to 3 eyes (21.4\%), and at year two, no eye fulfilled the threshold. Considering a pachychoroid threshold of $\geq 300 \mu \mathrm{m}, 13$ out of the 14 PNV eyes (92.9\%) exceeded this value at baseline. After anti-VEGF treatment, this figure dropped to 4 eyes (28.5\%) at year one, and one eye (9.1\%) at year two

reliable long-term diagnostic criterium. At two years, after mean 13 anti-VEGF injections, the PNV eyes included in this study showed a mean SFCT reduction by $39 \%$ to a final value of $241 \mu \mathrm{m}$, making them, without knowledge of the status quo ante at baseline, ineligible for a pachychoroid diagnosis based on above mentioned threshold. This resonates with recent findings on various treatment regimen for PNV [16, 23].

From a clinical perspective, the percentage of eyes presenting with a pachychoroid $>350 \mu \mathrm{m}$ decreased from $86 \%$ at baseline to $21 \%$ at year one, and $0 \%$ at year two. While it is difficult to give a definite threshold above which choroidal thickness becomes pathological, Cheung et al. state in their major review of the pachychoroid spectrum that "a value exceeding $300 \mu \mathrm{m}$ will mostly be regarded as pathological" [2]. This is mainly based on a series of older an newer studies, in which normal subfoveal choroidal thickness was found to be around $300 \mu \mathrm{m}$ on average (Margolis and Spaide [24] $287 \mu \mathrm{m}$, Manjunath et al. [25] $272 \mu \mathrm{m}$, Ikuno et al. [26]354 $\mu \mathrm{m}$, Akhtar et al. [13] $307 \mu \mathrm{m})$. Applying this lower threshold of $300 \mu \mathrm{m}$ to our study, $93 \%$ of eyes fulfilled this criterium at baseline - a figure which however also dropped to $29 \%$ at year one, and $9 \%$ at year two.

Strikingly, not all eyes included in this analysis showed a classic "pachychoroid" of $>350 \mu \mathrm{m}$ at baseline - even though their "pachychoroid" origin was determined by pre-documented CSC in these eyes. Many factors have been shown to influence SFCT, mainly age [13] and axial length [27]. Akhtar et al. for example found a mean subfoveal thickness of $327 \pm 68 \mu \mathrm{m}$ for participants aged 1218 years, as opposed to a mean $262 \pm 72 \mu \mathrm{m}$ in participants above 60 years [13]. In a study by FloresMoreno et al. [27], choroidal thickness decreased by approximately $26 \mu \mathrm{m}$ per every additional $\mathrm{mm}$ of axial length. In this context, our findings further establish anti-VEGF therapy as an important influence on choroidal thickness. In both year one and two, we saw a significant strong correlation of choroidal thinning and the amount of anti-VEGF injections applied. While these data already give a strong hint towards a possible connection, they are at the same time confirmed by the fact that the untreated partner eyes did not show any significant changes in choroidal thickness, though they largely also suffered from a pachychoroid and pachychoroidrelated disease (pachychoroid pigment epitheliopathy, CSC without CNV). This difference between PNV and partner eyes, as well as the follow-up of just below two years should make the influence of aging as a confounding factor rather negligible.

Thinning of the choroid under anti-VEGF has been previously reported for diabetic macular edema [28], neovascular AMD [14], retinal vein occlusion [29] and myopic CNV [30], although some results are conflicting [31]. It is currently unclear which specific changes in the choroid contribute to its thinning during the course of intravitreal anti-VEGF therapy for PNV. Progresive damage to the choriocapillaris, and maybe even Sattler's layer in advanced cases, which PNV certainly signifies $[1,2$, 32], might hint at the pathologically dilated Haller's layer to be the primary location of anti-VEGF action. Within Haller's layer itself, decreases in luminal or stromal, or both departments may be responsible. Recent data analyzing choroidal changes in aging have found that both 
choroidal stromal and vessel volume decrease in a similar manner, maintaining the choroidal vascularity index (CVI) unaltered [33]. If pachychoroid disorders are to be understood as vascular congestion [34], and if the therapeutic effect of anti-VEGF should rely in partially alleviating this congestion, it might be intuitive to expect more luminal than stromal changes. Indeed, a recent study analyzing the effect of anti-VEGF on PCV (belonging to the same pathophysiological spectrum as PNV) found that the greatest vertical choroidal vessel diameter indicating choroidal lumina significantly decreased with anti-VEGF administration, and increased again prior to the reappearance of macular fluid on OCT. [35] These findings suggest that choroidal thickening in pachychoroid disorders might not only be secondary to dilated, congested vessels with increased diameter due to increased lumen, but also due to leakage from the choroidal lumina into the stroma. With this hypothesis, the thinning effects of anti-VEGF on the choroid might be most intuitively explained by a reduction of choroidal leakage from pachyvessels, and thus less stroma swollen by leaked fluid. Due to this dual action, eyes with PNV might require less injections than type $1 \mathrm{CNV}$ in $\mathrm{AMD}$, and visual acuity results might be better as recently suggested [36]. On the contrary, photodynamic therapy might be beneficial if anti-VEGF manages CNV, but fails to normalize choroidal congestion [37].

Our data directly translate into possible recommendations as how to diagnose PNV. Choroidal thickness should be referenced at baseline, and not used as a diagnostic criterium after commencing anti-VEGF treatment. Moreover, our data also indirectly translate into a better distinction of neovascular pachychoroid disease and agerelated macular degeneration (nAMD) [38, 39]. It is conceivable that a certain percentage of presumed neovascular AMD, in reality, represents PNV. A relatively high incidence of misdiagnosis might be aggravated by the fact that choroidal thickness does not serve as a good differentiator between both entities in the chronic, antiVEGF treatment phase. It is these chronically ill eyes, however, in which "AMD non-response" is mostly evaluated - and where PNV can serve as an important differential diagnosis bearing treatment decisions regarding on disease-specific biomarkers. While persistent subretinal fluid, for example, can potentially be tolerated in nAMD [40], it will inevitably lead to progressive foveal thinning in pachychoroid disease [41], for which several additional treatment options are under current investigation, including mineralocorticoid receptor antagonists $[42,43]$, photodynamic therapy, or non-damaging laser treatments [44]. These options should not be withheld to a patient based on a false diagnosis of presumed nAMD. For these reasons, other biomarkers of pachychoroid disease should be first choice apart from sole choroidal thickness when the eye in question presents with a history of anti-VEGF treatment. These biomarkers include, e.g., the presence of dilated Haller veins, called pachyvessels, an increased choroidal vascularity index, and choroidal hyperpermeability [2, 45].

Certain limitations of our study can be found. First of all, our sample size as well as follow-up are limited. Moreover, we cannot give a detailed analysis of choroidal perfusion changes under anti-VEGF therapy as we lack consistent long-term OCT angiography data. Moreover, $14 \%$ of PNV eyes included in this study already presented with SFCT below the $350 \mu \mathrm{m}$ pachychoroid threshold before commencing anti-VEGF therapy; in these eyes, however, the diagnosis of PNV was confirmed due to a pre-documented history of chronic CSC. Another statistical limitation lies within the inclusion of both eyes of every patient, which indicates that the data of the treatment and control group are not statistically independent. This limitation however cannot be overcome as this study was specifically designed to include the partner eye as an intra-individual control which undergoes the same systemic factors influencing SFCT as in the treated eye (e.g. blood pressure, systemic glucocorticoid levels, aging).

In conclusion, this study demonstrates that choroidal thickness in PNV significantly decreases with anti-VEGF therapy, resembling a "vanishing pachy-choroid". Thus, choroidal thickness does not represent a valid long-term diagnostic criterium and cannot be used as a safe differentiator from nAMD in these cases [46, 47]. Further analyses of pachychoroid biomarkers beyond sole thickness are warranted, e.g. towards choroidal vascularity index and choroidal stroma-to-vessel volume ratio, which might represent more stable, anti-VEGF independent biomarkers in the diagnosis of neovascular and non-neovascular pachychoroid disease [46].

\section{Abbreviations}

BAF: blue autofluorescence; CNV: Choroidal Neovascularization; CSC: Central serous chorioretinopathy; CSLO: confocal scanning laser ophthalmoscopy; CT: Choroidal Thickness; EDI: Enhanced depth imaging; FA: Fluorescein angiography; ICGA: Indocyanine green angiography; nAMD: Neovascular agerelated macular Degeneration; NIR: Near-infrared reflectance; OCT: Optical coherence tomography; PNV: Pachychoroid neovasculopathy; SFCT: Subfoveal choroidal thickness; VEGF: Vascular endothelial growth factor

\section{Acknowledgements}

This study was presented at the 118th annual meeting of the German Ophthalmological Society, Berlin 2020.

\section{Authors' contributions}

JS, LFK and BS performed multimodal imaging analysis. JS, LFK, BS, NL, TCK, TRH and SGP interpreted the data. JS created the graphs. JS drafted the manuscript. JS, LFK, BS, NL, TCK, TRH and SGP developed the manuscript into its final version.

\section{Funding}

The authors report no funding. Open Access funding enabled and organized by Projekt DEAL. 


\section{Availability of data and materials}

Data will be made available upon reasonable request.

\section{Declarations}

\section{Ethics approval and consent to participate}

Institutional review board (University Eye Hospital Munich, LudwigMaximilians-University Munich) approval was obtained for this retrospective chart review, and the study adhered to the tenets of the Declaration of Helsinki. All patients provided written consent.

\section{Consent for publication}

None applicable, as no uniquely identifying information about a single subject are given.

\section{Competing interests}

No author reports any financial interest relevant to this study. Benedikt Schworm received previous speaker fees and travel expenses from Novartis Pharma GmbH and Topcon Corporation. Nikolaus Luft received income from honoraria as a lecturer from Alcon Laboratories Inc., NIDEK Co. Ltd. and CenterVue SpA. Leonie F Keidel received income from honoraria as a lecturer from Recordati Pharma GmbH. Thomas C Kreutzer received previous speaker fees from Alcon Pharma $\mathrm{GmbH}$. Thomas $\mathrm{C}$ Kreutzer received personal consultation fees from Novartis Pharma GmbH and Bayer AG. Thomas C Kreutzer received travel reimbursement from D.O.R.C. (International) B.V. Karsten Kortuem received previous speaker fees and/or travel expenses from Novartis Pharma GmbH, Bayer AG, and Alcon Pharma $\mathrm{GmbH}$. Karsten Kortüm received personal consultation fees from Big Picture Medical. Karsten Kortüm received travel expenses from Pharm-Allergan $\mathrm{GmbH}$ and Heidelberg Engineering GmbH. Armin Wolf received previous speaker fees and research funds from Novartis Pharma GmbH, Oertli AG, Bayer AG, Pharm-Allergan GmbH and Alimera Sciences Ophthalmologie $\mathrm{GmbH}$. Tina Rike Herold received income from honoraria as a lecturer from Novartis GmbH, Bayer AG and Pharm-Allergan GmbH. Siegfried Priglinger received previous speaker fees and/or travel expenses from Novartis Pharma $\mathrm{GmbH}$, Oertli AG, Bayer AG, Alcon Pharma GmbH and Pharm-Allergan GmbH. Jakob Siedlecki received previous speaker honoraria, personal consultation honoraria and travel expenses from Novartis Pharma GmbH, Bayer AG, Roche AG, Carl Zeiss Meditec AG, Oculentis OSD Medical GmbH and Allergan $\mathrm{GmbH}$.

Received: 19 April 2021 Accepted: 8 June 2021

Published online: 30 June 2021

\section{References}

1. Mrejen S, Balaratnasingam C, Kaden TR, Bottini A, Dansingani K, Bhavsar KV, et al. Long-term visual outcomes and causes of vision loss in chronic central serous Chorioretinopathy. Ophthalmology. 2019;126(4):576-88. https://doi. org/10.1016/j.ophtha.2018.12.048.

2. Cheung CMG, Lee WK, Koizumi H, Dansingani K, Lai TYY, Freund KB. Pachychoroid disease. Eye. 2019;33(1):14-33. https://doi.org/10.1038/s41433018-0158-4.

3. Bonini Filho MA, de Carlo TE, Ferrara D, Adhi M, Baumal CR, Witkin A, et al. Association of Choroidal Neovascularization and Central Serous Chorioretinopathy with Optical Coherence Tomography Angiography. JAMA Ophthalmol. 2015; 133(8):899-906. https://doi.org/10.1001/jamaophthalmol.2015.1320.

4. Pang CE, Freund KB. Pachychoroid neovasculopathy. Retina. 2015;35(1):1-9. https://doi.org/10.1097//AE.0000000000000331.

5. Hwang H, Kim JY, Kim KT, Chae JB, Kim DY. Flat irregular pigment epithelium detachment in central serous chorioretinopathy: a form of Pachychoroid Neovasculopathy? Retina. 2020;40(9):1724-33. https://doi.org/1 0.1097/IAE.0000000000002662.

6. Siedlecki J, Schworm B, Priglinger SG. The Pachychoroid Disease Spectrumand the Need for a Uniform Classification System. Ophthalmol Retina. 2019; 3(12):1013-5. https://doi.org/10.1016/j.oret.2019.08.002.

7. Fung AT, Yannuzzi LA, Freund KB. Type 1 (sub-retinal pigment epithelial) neovascularization in central serous chorioretinopathy masquerading as neovascular age-related macular degeneration. Retina. 2012;32(9):1829-37. https://doi.org/10.1097/IAE.0b013e3182680a66.

8. Querques G, Souied EH. Vascularized Drusen: slowly progressive type 1 neovascularization mimicking Drusenoid retinal pigment epithelium elevation. Retina. 2015;35(12):2433-9. https://doi.org/10.1097/IAE. 0000000000000761.

9. Rosenfeld PJ, Brown DM, Heier JS, Boyer DS, Kaiser PK, Chung CY, et al. Ranibizumab for neovascular age-related macular degeneration. N Engl J Med. 2006;355(14):1419-31. https://doi.org/10.1056/NEJMoa054481.

10. Cho HJ, Jung SH, Cho S, Han JO, Park S, Kim JW. Intravitreal anti-vascular endothelial growth factor treatment for Pachychoroid Neovasculopathy. J Ocul Pharmacol Ther. 2019;35(3):174-81. https://doi.org/10.1089/jop.2018.0107.

11. Jung BJ, Kim JY, Lee JH, Baek J, Lee K, Lee WK. Intravitreal aflibercept and ranibizumab for pachychoroid neovasculopathy. Sci Rep. 2019;9(1):2055. https://doi.org/10.1038/s41598-019-38504-y.

12. Wei WB, Xu L, Jonas JB, Shao L, du KF, Wang $S$, et al. Subfoveal choroidal thickness: the Beijing eye study. Ophthalmology. 2013;120(1):175-80. https:/ doi.org/10.1016/j.ophtha.2012.07.048.

13. Akhtar Z, Rishi P, Srikanth R, Rishi E, Bhende M, Raman R. Choroidal thickness in normal Indian subjects using swept source optical coherence tomography. PLoS One. 2018;13(5):e0197457. https://doi.org/10.1371/journal.pone.0197457.

14. Gharbiya M, Giustolisi R, Marchiori J, Bruscolini A, Mallone F, Fameli V, et al. Comparison of short-term choroidal thickness and retinal morphological changes after intravitreal anti-VEGF therapy with Ranibizumab or Aflibercept in treatment-naive eyes. Curr Eye Res. 2018;43(3):391-6. https://doi.org/10.1 080/02713683.2017.1405045.

15. Mazaraki K, Fassnacht-Riederle H, Blum R, Becker M, Michels S. Change in choroidal thickness after intravitreal aflibercept in pretreated and treatmentnaive eyes for neovascular age-related macular degeneration. $\mathrm{Br} J \mathrm{Ophthalmol}$. 2015;99(10):1341-4. https://doi.org/10.1136/bjophthalmol-2015-306636.

16. Padrón-Pérez N, Arias L, Rubio M, Lorenzo D, García-Bru P, Català-Mora J, et al. Changes in choroidal thickness after intravitreal injection of anti-vascular endothelial growth factor in Pachychoroid Neovasculopathy. Invest Ophthalmol Vis Sci. 2018:59(2):1119-24. https://doi.org/10.1167/iovs.17-22144.

17. Schworm B, Luft N, Keidel LF, et al. Vanishing pachy-choroid in pachychoroid neovasculopathy under long-term anti-vascular endothelial growth factor therapy. Presented at the German Ophthalmological Society Meeting 2020. Ophthalmologe. 2020;117(Suppl 2):S43-S190. https://doi. org/10.1007/s00347-020-01197-0.

18. Lau JK, Cheung SW, Collins MJ, Cho P. Repeatability of choroidal thickness measurements with Spectralis OCT images. BMJ Open Ophthalmol. 2019; 4(1):e000237. https://doi.org/10.1136/bmjophth-2018-000237.

19. Yamashita T, Yamashita T, Shirasawa M, Arimura N, Terasaki H, Sakamoto T. Repeatability and reproducibility of subfoveal choroidal thickness in Normal eyes of Japanese using different SD-OCT devices. Invest Ophthalmol Vis Sci. 2012;53(3):1102-7. https://doi.org/10.1167/iovs.11-8836.

20. Freund KB, Korobelnik JF, Devenyi R, Framme C, Galic J, Herbert E, et al. TREAT-AND-EXTEND REGIMENS WITH ANTI-VEGF AGENTS IN RETINAL DISE ASES: a literature review and consensus recommendations. Retina. 2015; 35(8):1489-506. https://doi.org/10.1097//AE.0000000000000627.

21. Matsumoto H, Hiroe T, Morimoto M, Mimura K, Ito A, Akiyama H. Efficacy of treat-and-extend regimen with aflibercept for pachychoroid neovasculopathy and type 1 neovascular age-related macular degeneration. Jpn J Ophthalmol. 2018;62(2):144-50. https:/doi.org/10.1007/s10384-018-0562-0.

22. Kuroda S, Ikuno Y, Yasuno Y, Nakai K, Usui S, Sawa M, et al. Choroidal thickness in central serous chorioretinopathy. Retina. 2013;33(2):302-8. https://doi.org/10.1097/IAE.0b013e318263d11f.

23. Elfandi S, Ooto S, Miyata M, et al. Effects of Intravitreous Aflibercept Injection in Pachychoroid Neovasculopathy: Comparison with Typical Neovascular AgeRelated Macular Degeneration. Clin Ophthalmol. 2021;15:1539-49.

24. Margolis R, Spaide RF. A pilot study of enhanced depth imaging optical coherence tomography of the choroid in normal eyes. Am J Ophthalmol. 2009;147(5):811-5. https://doi.org/10.1016/j.ajo.2008.12.008.

25. Manjunath V, Taha M, Fujimoto JG, Duker JS. Choroidal thickness in normal eyes measured using Cirrus HD optical coherence tomography. Am J Ophthalmol. 2010;150(3):325-329.e321.

26. Ikuno Y, Kawaguchi $K$, Nouchi T, Yasuno Y. Choroidal thickness in healthy Japanese subjects. Invest Ophthalmol Vis Sci. 2010;51(4):2173-6. https://doi. org/10.1167/iovs.09-4383.

27. Flores-Moreno I, Lugo F, Duker JS, Ruiz-Moreno JM. The relationship between axial length and choroidal thickness in eyes with high myopia. Am J Ophthalmol. 2013;155(2):314-319.e311.

28. Yiu G, Manjunath V, Chiu SJ, Farsiu S, Mahmoud TH. Effect of anti-vascular endothelial growth factor therapy on choroidal thickness in diabetic macular edema. Am J Ophthalmol. 2014;158(4):745-751.e742. 
29. Kida T, Osuka S, Fukumoto M, Sato T, Harino S, Oku H, et al. Long-term follow-up changes of central choroidal thickness thinning after repeated anti-VEGF therapy injections in patients with central retinal vein occlusionrelated macular edema with systemic hypertension. Ophthalmologica. 2020; 243(2):102-9. https://doi.org/10.1159/000504754.

30. Lee JH, Lee SC, Kim SH, Koh HJ, Kim SS, Byeon SH, et al. Choroidal thickness and CHORIORETINAL ATROPHY in myopic choroidal neovascularization with anti-vascular endothelial growth factor therapy. Retina. 2017;37(8):1516-22. https://doi.org/10.1097/IAE.0000000000001384.

31. Ellabban AA, Tsujikawa A, Ogino K, et al. Choroidal thickness after intravitreal ranibizumab injections for choroidal neovascularization. Clin Ophthalmol. 2012;6:837-44.

32. Siedlecki J, Schworm B, Priglinger SG. The Pachychoroid disease Spectrumand the need for a uniform classification system. Ophthalmol Retina. 2019; 3(12):1013-5. https://doi.org/10.1016/j.oret.2019.08.002.

33. Zhou H, Dai Y, Shi Y, Russell JF, Lyu C, Noorikolouri J, et al. Age-related changes in choroidal thickness and the volume of vessels and stroma using swept-source OCT and fully automated algorithms. Ophthalmol Retina. 2020:4(2):204-15. https://doi.org/10.1016/j.oret.2019.09.012.

34. Matsumoto $H$, Kishi S, Mukai R, Akiyama $H$. Remodeling of macular vortex veins in pachychoroid neovasculopathy. Sci Rep. 2019;9(1):14689. https://doi. org/10.1038/s41598-019-51268-9.

35. Nagai N, Suzuki M, Minami S, Kurihara T, Kamoshita M, Sonobe H, et al. Dynamic changes in choroidal conditions during anti-vascular endothelial growth factor therapy in polypoidal choroidal vasculopathy. Sci Rep. 2019; 9(1):11389. https://doi.org/10.1038/s41598-019-47738-9.

36. You Jl, Kim K. Comparative analysis of the clinical features and long-term outcomes of Pachychoroid Neovasculopathy and type 1 Neovascular agerelated macular degeneration. J Ophthalmol. 2020;2020:8865743.

37. Hikichi T, Kubo N, Yamauchi M. One-year comparison of anti-vascular endothelial growth factor and half-dose photodynamic therapies for pachychoroid neovasculopathy. Eye (Lond). 2021. https://doi.org/10.1038/ s41433-021-01418-z.

38. Thulliez M, Zhang $\mathrm{Q}$, Shi $Y$, Zhou H, Chu Z, de Sisternes L, et al. Correlations between Choriocapillaris flow deficits around geographic Atrophy and enlargement rates based on swept-source OCT imaging. Ophthalmol Retina. 2019;3(6):478-88. https://doi.org/10.1016/j.oret.2019.01.024.

39. Whitmore SS, Sohn EH, Chirco KR, Drack AV, Stone EM, Tucker BA, et al. Complement activation and choriocapillaris loss in early AMD: implications for pathophysiology and therapy. Prog Retin Eye Res. 2015;45:1-29. https:// doi.org/10.1016/j.preteyeres.2014.11.005.

40. Guymer RH, Markey CM, McAllister IL, Gillies MC, Hunyor AP, Arnold JJ. Tolerating subretinal fluid in Neovascular age-related macular degeneration treated with Ranibizumab using a treat-and-extend regimen: FLUID study 24-month results. Ophthalmology. 2019;126(5):723-734. https://doi.org/10.1 016/j.ophtha.2018.11.025

41. Breukink MB, Dingemans AJ, den Hollander Al, et al. Chronic central serous chorioretinopathy: long-term follow-up and vision-related quality of life. Clin Ophthalmol. 2017:11:39-46.

42. Bousquet E, Beydoun T, Rothschild PR, Bergin C, Zhao M, Batista R, et al. Spironolactone for Nonresolving central serous Chorioretinopathy: a randomized controlled crossover study. Retina. 2015;35(12):2505-15. https:// doi.org/10.1097/IAE.0000000000000614

43. Bousquet E, Beydoun T, Zhao M, Hassan L, Offret O, Behar-Cohen F. Mineralocorticoid receptor antagonism in the treatment of chronic central serous chorioretinopathy: a pilot study. Retina. 2013;33(10):2096-102. https://doi.org/10.1097//AE.0b013e318297a07a.

44. van Dijk EHC, Fauser S, Breukink MB, Blanco-Garavito R, Groenewoud JMM, Keunen JEE, et al. Half-dose photodynamic therapy versus high-density subthreshold micropulse laser treatment in patients with chronic central serous Chorioretinopathy: the PLACE trial. Ophthalmology. 2018;125(10): 1547-55. https://doi.org/10.1016/j.ophtha.2018.04.021.

45. Agrawal R, Chhablani J, Tan KA, Shah S, Sarvaiya C, Banker A. Choroidal vascularity index in central serous chorioretinopathy. Retina. 2016;36(9): 1646-51.

46. Zhou H, Dai Y, Lyu C, et al. Age-related changes in choroidal thickness and the volume of vessels and stroma using swept source OCT and fully automated algorithms. Ophthalmol Retina. 2020;4(2):204-215. https://doi. org/10.1016/j.oret.2019.09.012.

47. Keidel LF, Schworm B, Priglinger SG, Siedlecki J. Pachychoroid Neovasculopathy Disguising as Age-Related Macular Degeneration Treated by Spironolactone and Anti-VEGF Combination Therapy. Case Rep Ophthalmol. 2021;12(1):116-23. https://doi.org/10.1159/000510828.

\section{Publisher's Note}

Springer Nature remains neutral with regard to jurisdictional claims in published maps and institutional affiliations.
Ready to submit your research? Choose BMC and benefit from:

- fast, convenient online submission

- thorough peer review by experienced researchers in your field

- rapid publication on acceptance

- support for research data, including large and complex data types

- gold Open Access which fosters wider collaboration and increased citations

- maximum visibility for your research: over $100 \mathrm{M}$ website views per year

At $\mathrm{BMC}$, research is always in progress.

Learn more biomedcentral.com/submissions 